\title{
Improving Grape Quality Using Microwave Vacuum Drying Associated with Temperature Control
}

\author{
C. D. Clary, E. Mejia-Meza, S. Wang, and V. E. Petrucci
}

\begin{abstract}
Microwave (MW) vacuum dehydration using temperature to control the level of MW power demonstrated potential in improving the performance of the process. Product surface temperature measured by an infrared temperature sensor was used to control MW power at any level between 0 and $3 \mathrm{~kW}$. Multiple linear regression analysis indicated an $r^{2}=0.942$ for prediction of final moisture content and $r^{2}=0.985$ for prediction of puffed character of grapes based on product temperature, time, specific energy, fresh fruit sugar, and fresh fruit moisture content. Temperature was found to be the most significant predictor. The elemental and compound contents of grapes dried using MW vacuum was compared to sun-dried raisins. The grapes dried using MW vacuum exhibited better preservation. Vitamin A was found in the MW-vacuum-dried grapes but none was detected in the raisins, and Vitamin C, thiamine, and riboflavin were also higher in the MW-vacuum-dried grapes than in the raisins.

Keywords: grapes, microwave vacuum dehydration, nutrition, raisins, specific energy
\end{abstract}

\section{Introduction}

$\mathrm{D}$ ehydration has been extensively utilized for decades as one of the principal food preservation techniques. The intent of this process is to produce shelf stable foods with specific applications and sensory characteristics. Currently, conventional thermal methods such as sun drying and hot-air drying are used in the food industry to preserve fruits and vegetables. However, the quality of conventionally dried fruits is affected, and there is little resemblance to the fresh fruit (Ratti 2001). Sun-dried grapes produce raisins with a worldwide production of about 600000 tons, more than half produced in California with a value of $\$ 125$ million in 2000 (FASOnline 2002). Prolonged exposure to sunlight and heat causes a reduction in nutritional and elemental contents. Vacuum drying and freeze drying are alternatives to dry sensitive fresh fruit products to low final moisture content (FMC), but these methods are costly and require high labor or high capital investment as well as longer periods of drying time (Kyzlink 1990).

Microwave (MW) vacuum dehydration has the potential for preserving fruit while maintaining nutritional and functional characteristics. Research has been conducted using this drying method for producing high-quality dried fruits and vegetables (Mousa and Farid 2002; Mui and others 2002; Cui and others 2004; Sunjka and others 2004; Clary and others 2005). MW heating is based on a physical phenomenon generated by the interaction between electromagnetic waves and foods. Dipole rotation and ionic conduction are the 2 most important phenomena occurring during the MW heating. With dipole rotation, when polar molecules such as water are exposed to an MW field, the rapid change in the direction of the

MS 20060355 Submitted 6/21/2006, Accepted 10/26/2006. Author Clary is with Horticulture and Landscape Architecture, Washington State Univ., Pullman, WA 99164-6414. Author Mejia-Meza is with Food Science and Human Nutrition, Washington State Univ., Pullman, WA 99164-6376. Author Wang is with Biological Systems Engineering, Washington State Univ., Pullman, WA 99164-6120. Author Petrucci is with Emeritus, Viticulture and Enology Research Center, California State Univ., Fresno, CA 937400089. Direct inquiries to author Clary (E-mail: cclary@wsu.edu). electric field causes the water molecules to attempt to align in the direction of the electric field. As the molecules agitate, heat is generated. In ionic conduction, heat is generated because of the increase mobility of the ions caused by the exposure of them to an MW field (Schiffmann 1995; Drouzas and Schubert 1996; Feng and Tang 1998). MW drying under vacuum reduces the boiling point of water within the food material, so that the process temperature is lower than that at atmospheric pressure.

The combination of MW heating and vacuum makes this dehydration method rapid and more energy efficient than some of the conventional drying methods (Clary and others 2005; Zhang and others 2006; Giri and Prasad 2007). Drouzas and others (1999) applied an MW power range of 640 to $710 \mathrm{~W}$ and vacuum pressure of 3 to $5 \mathrm{kPa}$ to determine the drying kinetics of model fruit gels simulating orange juice concentrate. The combination of MW heating and vacuum drying accelerated the drying rate of model fruit juice. Cui and others (2004) studied the drying kinetics of carrot slices based on a theoretical model. McMinn (2006) used semitheoretical and empirical thin-layer drying modeling equations to describe the drying characteristics of lactose-water samples dried using hot air, MW, MW-hot air, and MW vacuum. The researchers concluded that the system pressure and occurrence/absence of external heating/cooling sources affected the drying rate.

Drying characteristics of fruits and vegetables dried by MW vacuum dehydration alone or combined with hot-air drying have been studied. Hu and others (2006) compared the characteristics of hot air, MW vacuum, and the combination of both using edamame (soybean) as a food material. They found that the combined drying processes decreased in drying time and mass loads and improved product quality compared with conventional hot-air drying or MW vacuum dehydration alone. In other research, Giri and Prasad (2007) evaluated the dehydration characteristics of button mushroom with the use of a commercial MW oven $(600 \mathrm{~W})$ modified by including a vacuum chamber in the cavity. They concluded that a decrease between $70 \%$ and $90 \%$ of drying time and better rehydration characteristics were achieved using MW vacuum compared to hot-air 
drying. The system pressure had little effect on the drying parameters; however, a significant effect was observed on the rehydration ratio. Clary and others (2005) investigated the effect of levels of MW power on the drying characteristics and moisture content of grapes by MW vacuum drying using 5 fixed levels and 3 stages of MW power levels. They reported that the optimum-specific energy determined by an energy balance model required to dry Thompson seedless grapes using MW vacuum dehydration was 0.97 to $1.01 \mathrm{~W}-\mathrm{h} / \mathrm{g}$ fresh grapes in the fixed levels of MW power. The specific energy was reported as the most influential parameter on the FMC of grapes in both fixed and incremental power level treatments. They concluded that the temperature of the fruit was the most significant factor in predicting the FMC of grapes and in providing a means to better control the process and improve the drying characteristics of the final product.

The objectives of this research were to determine the specific energy needed to dry grapes using MW vacuum dehydration based on temperature control, to explore the effect of the specific energy on the FMC and puffed character of grapes, and to compare the product nutritional content between MW vacuum and sun drying.

\section{Materials and Methods}

\section{Microwave vacuum drying system and grape samples}

The MW vacuum dehydrator (experimental prototype, McDonnell Douglas, St. Louis, Mo., U.S.A., a.k.a. Boeing) was used in the experiments. This $2450 \mathrm{MHz}, 3 \mathrm{~kW}$ test equipment is described by Clary and others (2005) (Figure 1 and 2). Fresh Thompson seedless grapes were separated from the cluster stems into samples weighing $1.8 \mathrm{~kg}$ for each replication. Fresh fruit sugar content was determined by refractometer (model 10482, Abbe/Scientific Instruments, Kleene, N.J., U.S.A.), and initial moisture content was determined by vacuum oven (AOAC 1980). Each treatment was replicated 3 times.

\section{Temperature-based treatments}

The specific energy used by Clary and others (2005) was $0.92 \mathrm{~W}-\mathrm{h} / \mathrm{g}$ fresh grapes when MW power was decreased in incremental stages as the grapes dried to an FMC of $3.5 \%$ (wb). As a result, specific energy was found to be the most significant factor in predicting FMC. Since the MW power application increased temperature, this may serve as a method to better control MW power application to optimize the drying process.

The MW vacuum dehydrator was equipped with an infrared temperature sensor (model H-L10000 infrared detector, Mikron, Oakland, N.J., U.S.A.) and control system to provide real-time control of the MW power. The sensor was mounted in a position that provided a field of view that included the turntable and grapes. A 0 to $1 V$ reference signal from the temperature sensor was connected to the MW control system. The emissivity of the treated grapes was set at 0.95 as a constant during the entire drying process because the vacuum vessel was dark. The MW power supply was equipped with an electromagnet surrounding the magnetron. This electromagnet was used to control the level of magnetic field in the magnetron interaction space. On the basis of the reference signal from the infrared temperature control system, the magnetic field was modulated to control the MW power output of the magnetron. When the surface temperature of the grapes approached the set point, the MW power was automatically reduced. Therefore, the output of the magnetron was determined by the temperature of the grapes in the process. The temperature control system was set to a maximum process temperature for each treatment. As the temperature of the grapes increased, the MW power decreased.

The MW power application for each test started at $3 \mathrm{~kW}$. The maximum surface treatment temperature levels were $54,60,66,71$, and $77^{\circ} \mathrm{C}$. The surface temperature of the grapes was measured continuously and recorded at 1 to $2 \mathrm{~min}$ intervals. Within each temperature treatment, $1.8 \mathrm{~kg}$ of fresh grapes were placed on the turntable in the vacuum vessel, subjected to a negative pressure of $2.7 \mathrm{kPa}$, and exposed to $3 \mathrm{~kW}$ of MW power. The purpose of the temperature

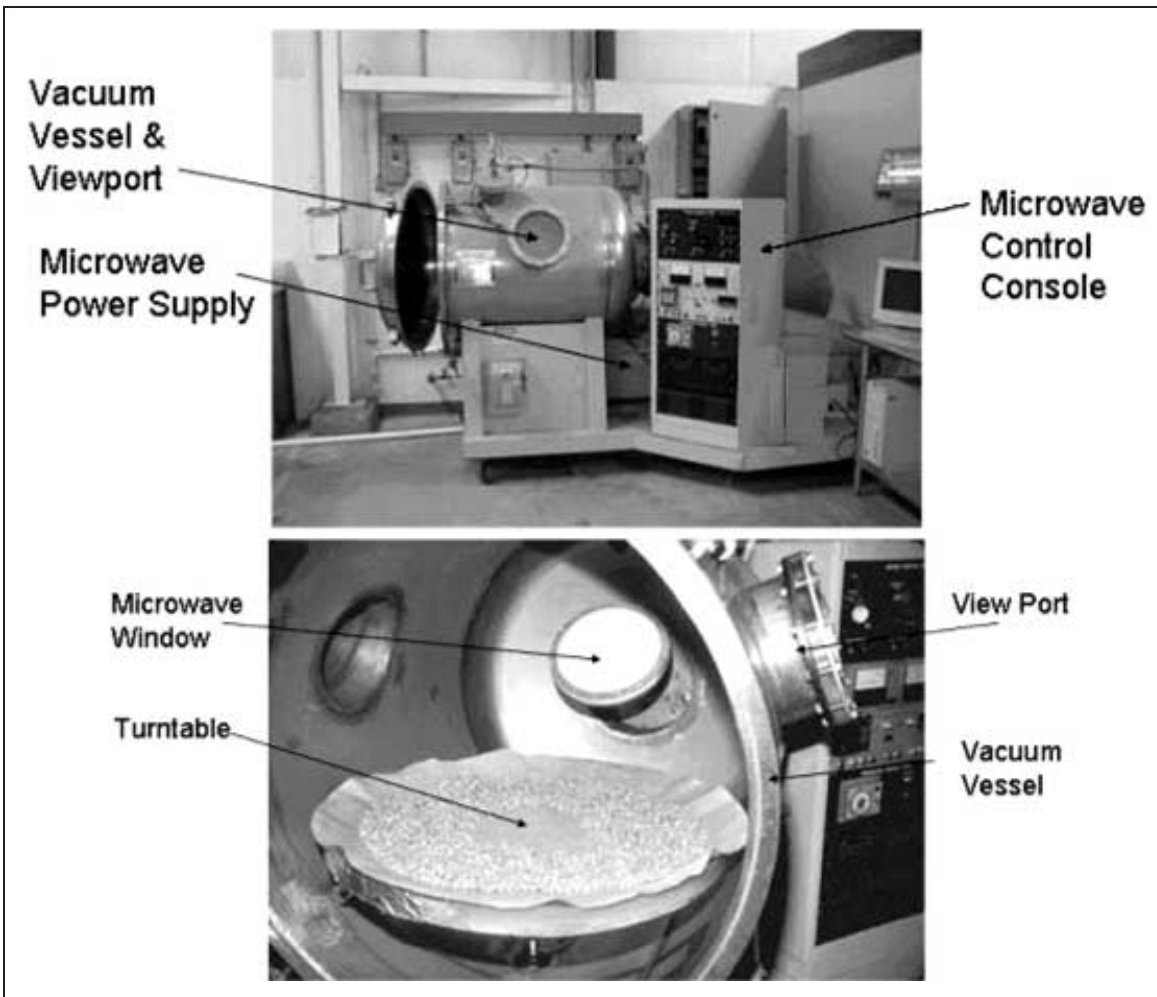

Figure 1 - Laboratory MW vacuum dehydration system (Clary and others 2005) 
control system was to control the level of MW power to ensure the grapes did not exceed the set treatment temperature. Termination of each test was determined on the basis of the evidence of burning, high-reflected power, and appearance of the dried grapes through an observation port.

The net MW power $\left(P_{n}\right)$ was calculated from the measured forward $\left(P_{f}\right)$ and reflected MW power $\left(P_{r}\right)$ by neglecting the power absorbed by the cavity (Eq. 1). This was based on Clary and others (2005), where the MW power loss to cavity was very small and could be neglected. The total specific energy, $E_{s}(\mathrm{~W}-\mathrm{h} / \mathrm{g}$ fresh product), for each test was calculated from the sum of the time intervals of each observation $\left(t_{i}\right)$, net MW power at each interval, and the mass of fresh grapes $(M)$, as defined by Clary and others (2005) as shown in Eq. 1 and 2.

$$
\begin{gathered}
P_{n}=P_{f}-\mathrm{P}_{r} \\
E_{s}=\frac{1}{60 M} \sum P_{i} t_{i}
\end{gathered}
$$

\section{Quality and statistical evaluation}

The nutrient element and compound contents of MW-vacuumdried grapes were compared with those of fresh fruit and sun-dried raisins. The sun-dried grapes were produced using the traditional California method (Petrucci and Clary 2002). Thompson seedless grapes were harvested by hand and placed on paper-drying trays in the vineyard row in early September when the daytime temperatures approached $40{ }^{\circ} \mathrm{C}$. Since the fruit was exposed to direct sunlight, the fruit temperature could reach $50{ }^{\circ} \mathrm{C}$ when the fruit was nearly dry. The fruit remained on the trays for 14 to $21 \mathrm{~d}$. Midway through the drying period, the trays were turned to uniformly dry the fruit. The dried raisins were collected and processed to an FMC of $18 \%$ (wb).

The grapes dried within each MW vacuum treatment were weighed and separated into categories of soft/chewy, puffed, and burnt. Each category was weighed. The grapes MW vacuum dried for $106 \mathrm{~min}$ at $71^{\circ} \mathrm{C}$ were evaluated for element and compound content and compared to fresh fruit and sun-dried raisins by Anresco Laboratory (San Francisco, Calif., U.S.A.) The contents covered protein, fat, carbohydrate, calories, vitamins A and C, thiamine, riboflavin, niacin, calcium, iron, sodium, potassium, crude fiber, moisture, ash, sulfur dioxide, and dietary fiber. The measurement methods of these parameters can be found elsewhere (Petrucci and Clary 2002). Because of the large quantity of parameters, the evaluation was made once to explore approximately the qualitative difference.

Temperature, time, specific energy, fresh fruit sugar, and fresh fruit moisture content were analyzed using multiple linear regression analysis (Minitab 14 2003) to develop surface plots and a prediction model for determining FMC and puffed content of the dried grapes.

\section{Results and Discussion}

\section{Microwave power, pressure, and temperature profiles of grapes}

An example of the profile of process parameters for MW vacuum dehydration of grapes at $66{ }^{\circ} \mathrm{C}$ is shown in Figure 3. Net MW power began at $2.8 \mathrm{~kW}$. A temperature rise in the surface temperature of the grapes was followed by a period of balance heating and cooling due to rapid vaporization. When the temperature of the grapes started increasing toward $66^{\circ} \mathrm{C}$, the temperature control started to decrease MW power. At $66^{\circ} \mathrm{C}$, the MW power decreased suddenly to less than $500 \mathrm{~W}$ for the remainder of the drying time. Vessel pressure increased in early stages owing to water vapor loading the vacuum pump. When evolution of moisture vapor slowed, the pressure returned to about $3 \mathrm{kPa}$. Specific energy was $0.804 \mathrm{~W}-\mathrm{h} / \mathrm{g}$ and FMC was $5.5 \%$ (Table 1) compared to $0.92 \mathrm{~W}$-h/g with the FMC of $3.5 \%$ reported by Clary and others (2005) using incremental levels of MW power.

The heating profile of grapes dried at 54 to $77^{\circ} \mathrm{C}$ is shown in Figure 4 . The curves showed 3 distinct drying segments. The 1 st segment showed the increase in sensible heat up to about 50 to $55^{\circ} \mathrm{C}$, followed by a segment of balanced heating and vaporization, and a final segment of heating holding at the constant temperature determined by the set-point temperature for each test. It is during this final segment that control of MW power using the set-point temperature provides the most critical control. In each drying treatment, the treatment temperature was reached at about 25 to $30 \mathrm{~min}$, at which time the MW power was reduced by the temperature contro system. Using the product temperature as a target, the drying process was more precise using real-time control of MW power and, in turn, saved the energy and improved the quality of the dried grapes. Similar temperature profiles have been reported by Lu and others (1999) in MW heating of potato slices, Feng and Tang (1998) in MW

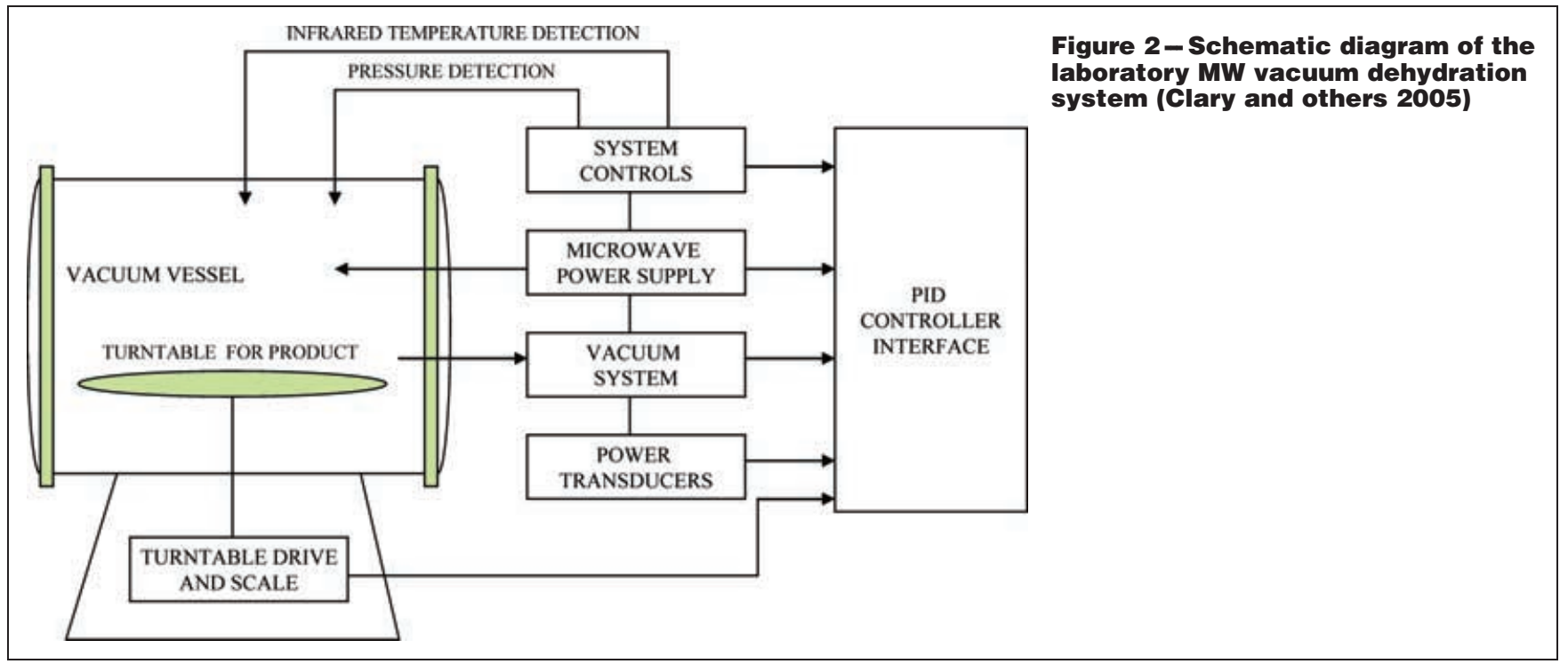


heating of apple dices, and by Clary and others (2005) in the dehydration of grapes heated in incremental levels. The balanced heating and vaporization were described as a balance of MW power and heat transfer from the product.

To begin to better understand the weight loss profile of grapes during drying, a preliminary test was conducted in which the grape sample was weighed in a process using a load cell added at the base of the shaft supporting the turntable holding the grapes. Weight was recorded every $5 \mathrm{~min}$ in a separate experiment to obtain these data. This will be the focus of future work and may provide information to calculate specific energy based on the moisture of fruit as it dries. As found in the tests reported earlier, the surface temperature of the grapes initially increased in response to full power heating. After about $10 \mathrm{~min}$, the grapes reached balanced heating and cooling (Figure 5), which was maintained until weight loss reached the falling rate part of the drying curve. At this point, the surface temperature

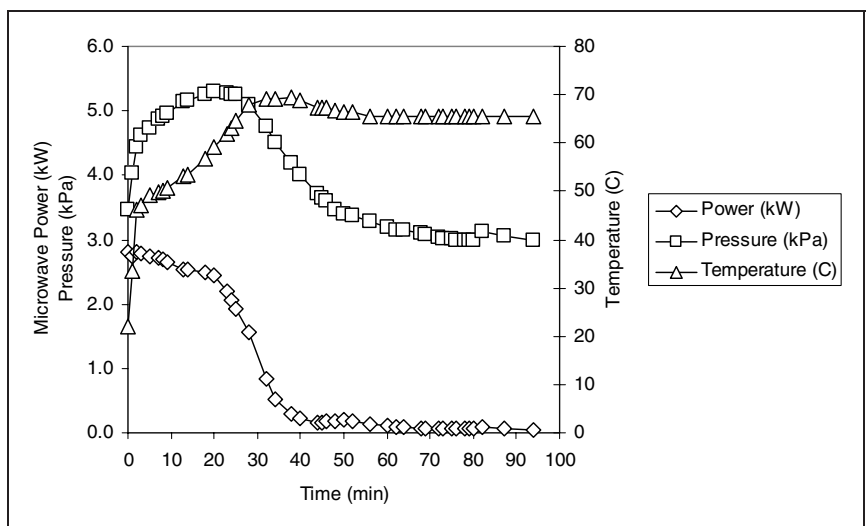

Figure 3-Example of the relationship of microwave power, pressure, and temperature of grapes during MW vacuum dehydration at $66^{\circ} \mathrm{C}$

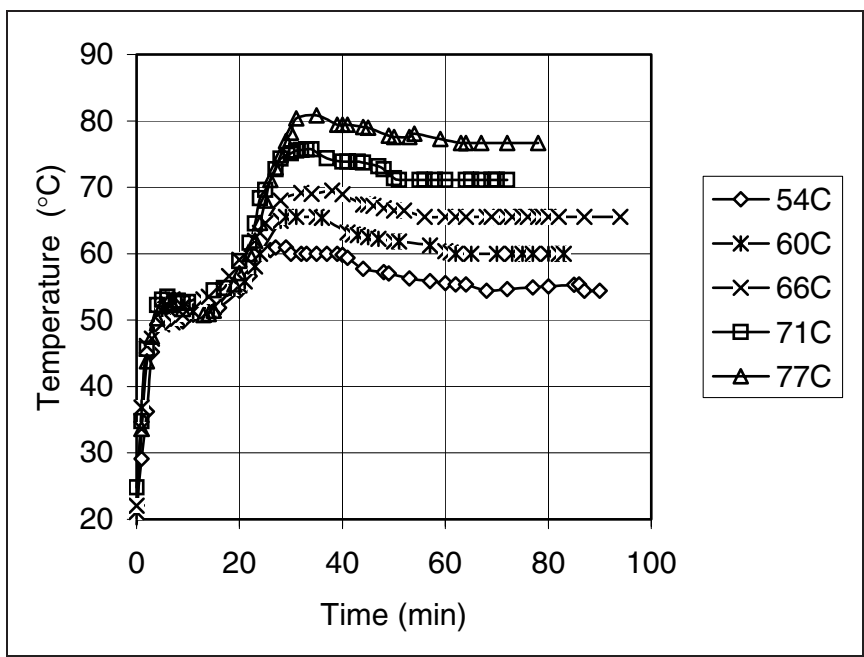

Figure 4-Comparison of heating profile of grapes dried at 5 temperatures of the grapes reached the set temperature of $66^{\circ} \mathrm{C}$ and MW power decreased to less than $500 \mathrm{~W}$ for the duration of the test.

\section{Multiple regression for final moisture contents}

The specific energy calculated using Eq. 1 and 2 ranged from 0.738 to $0.804 \mathrm{~W}$-h/g fresh product (Table 1 ). Lower specific energy was calculated at lower process temperature. As a result, FMC was higher and there were fewer grapes found to be puffed. As process temperature treatments were increased up to $71^{\circ} \mathrm{C}$, a higher portion of the grapes were puffed ( $80 \%$ ) and FMC decreased to $4.7 \%$. This process temperature seemed to be the optimum for the process.

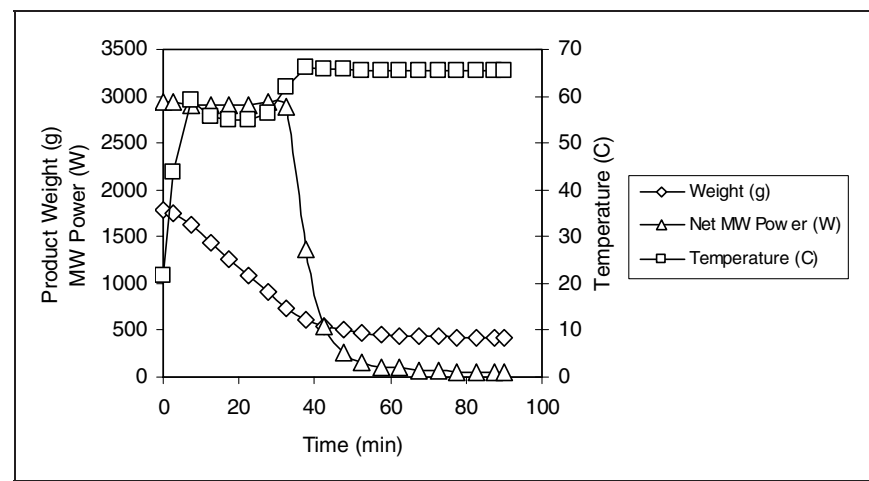

Figure 5-Weight loss profile of grapes dried at $66^{\circ} \mathrm{C}$

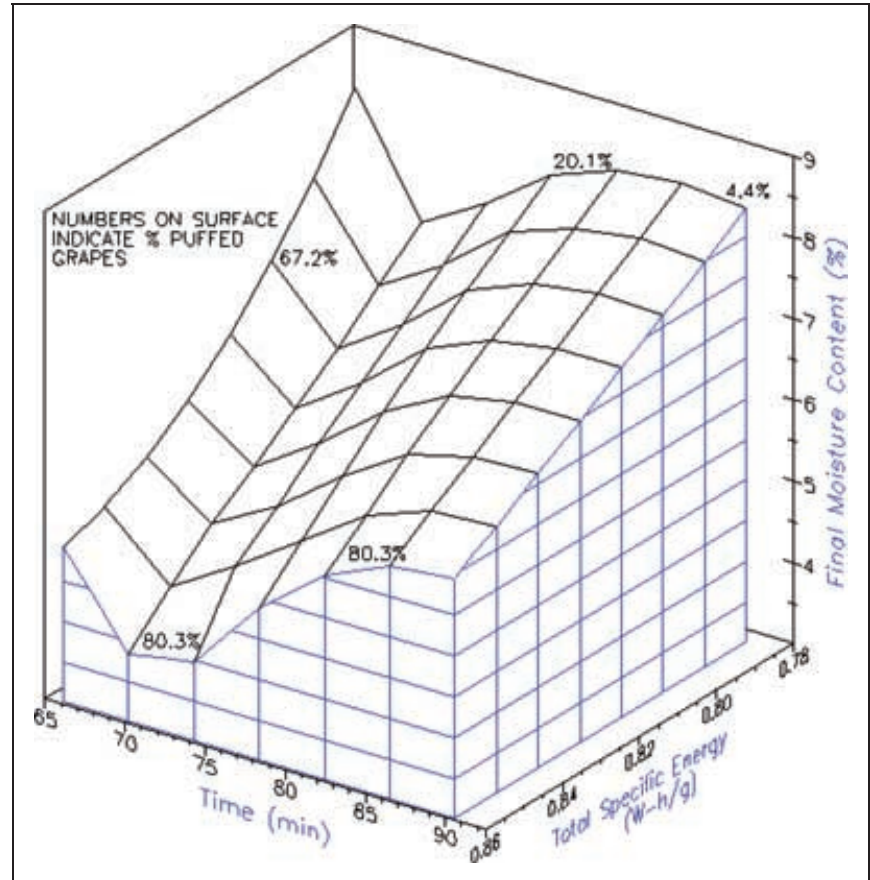

Figure 6-Regression surface plot of the effect of time and total specific energy on final moisture content at 54 to $77^{\circ} \mathrm{C}$

Table 1-Temperature control treatment levels, time and specific energy on final moisture content and appearance of grapes dried using MW vacuum dehydration (3 replications per treatment)

\begin{tabular}{lccccccc}
\hline $\begin{array}{l}\text { Test } \\
(\mathbf{n r})\end{array}$ & $\begin{array}{c}\text { Temperature } \\
\left({ }^{\circ} \mathbf{C}\right)\end{array}$ & $\begin{array}{c}\text { Time } \\
(\mathbf{m i n})\end{array}$ & $\begin{array}{c}\text { Chewy } \\
(\%)\end{array}$ & $\begin{array}{c}\text { Puffed } \\
(\%)\end{array}$ & $\begin{array}{c}\text { Burnt } \\
(\%)\end{array}$ & $\begin{array}{c}\text { Specific } \\
\text { energy (W-h/g) }\end{array}$ & $\begin{array}{c}\text { Final } \\
\text { moisture }(\% \text { wb) }\end{array}$ \\
\hline 1 & 54 & 92 & 94 & 4 & 2 & 0.738 & 8.0 \\
2 & 60 & 82 & 76 & 20 & 4 & 0.766 & 8.2 \\
3 & 66 & 94 & 14 & 80 & 6 & 0.742 & \\
4 & 71 & 72 & 8 & 80 & 11 & 4.7 \\
5 & 77 & 78 & 12 & 67 & 21 & 0.769 & 4.8 \\
\hline
\end{tabular}


A process temperature of $77^{\circ} \mathrm{C}$ resulted in a reduction in puffed character $(67 \%)$ and $21 \%$ of the sample was burned. Puffed character and crunchy texture are unique to grapes dried by MW vacuum and distinctively different from the collapse, wrinkled, and chewy texture of raisins.

Regression analysis using temperature, time, specific energy, and fresh fruit moisture and sugar content indicated that temperature was the most significant predictor of FMC $\left(r^{2}=0.942\right)$ (Table 2). Optimum time and specific energy were $70 \mathrm{~min}$ and $0.86 \mathrm{~W}$-h/g fresh product at a process temperature of $77^{\circ} \mathrm{C}$ (Figure 6). It is important to note that the specific energy shown in this surface plot was based on forward MW power $\left(P_{f}\right)$. Using this set of process parameters, predicted FMC is $4.0 \%$ with $80.3 \%$ of the grapes exhibiting puffed character.

Puffed character of grapes can be predicted using multiple linear regression analysis with an $r^{2}=0.985$ (Table 3). Temperature demonstrated the most significant predictor of puffed character as indicated by the decomposition of the sum of squares. Figure 7 shows the effects of specific energy and process temperature on the puffed character of grapes. The highest portion of puffed character was achieved using higher levels of specific energy and process temperature. A process temperature of $54{ }^{\circ} \mathrm{C}$ and a specific energy of $0.738 \mathrm{~W}$-h/g produced dried grapes with a low portion of puffed character and higher FMC (8.0\%). In treatments where temperature and specific energy were increased, a larger portion of the dried grapes were puffed and they had lower FMC, $80 \%$ and about $5.0 \%$, respectively. The surface regression plot indicates the highest por-

Table 2-Multiple regression analysis of the effect of temperature, time, total specific energy, fresh fruit sugar and initial moisture content on final moisture content of dried grapes $\left[\mathbf{Y}_{(\mathrm{FMC})}=\mathbf{b}_{0}+\mathbf{b}_{1}\left(\mathbf{x}_{1}\right)+\mathbf{b}_{2}\left(\mathbf{x}_{2}\right)+\mathbf{b}_{3}\left(\mathbf{x}_{3}\right)+\mathbf{b}_{4}\left(\mathbf{x}_{4}\right)+\right.$ $\left.b_{5}\left(x_{5}\right)\right]$

\begin{tabular}{llc}
\hline Variable & $\begin{array}{c}\text { Mean } \\
\text { response } \\
\text { coefficient }\end{array}$ & $\begin{array}{c}\text { Decomposition } \\
\text { [SSE }\end{array}$ \\
\hline Constant ISR $^{2}$
\end{tabular}

a Decomposition of the sum or squared errors $\left(\mathrm{SSE}_{\mathrm{Xi}}\right)$ indicated the amount $\mathrm{Xi}$ contributes to the prediction of $Y$.

$\mathrm{SSR}=$ sum or squared regression

Table 3-Multiple regression analysis of the effect of temperature, time, total specific energy, fresh fruit sugar, and initial moisture content on portion of dried grapes exhibiting puffed character $\left[\mathbf{Y}_{\text {Puffed }(\%)}=\mathbf{b}_{0}+\mathbf{b}_{1}\left(\mathbf{x}_{1}\right)+\mathbf{b}_{2}\left(\mathbf{x}_{2}\right)+\right.$ $\left.b_{3}\left(x_{3}\right)+b_{4}\left(x_{4}\right)+b_{5}\left(x_{5}\right)\right]$

\begin{tabular}{|c|c|c|}
\hline Variable & $\begin{array}{c}\text { Mean } \\
\text { response } \\
\text { coefficient }\end{array}$ & $\begin{array}{c}\text { Decomposition }^{\mathrm{a}} \\
\left.\text { [SSE }_{\mathrm{Xi}} / \mathrm{SSR}\right]^{2}\end{array}$ \\
\hline Constant & $b_{0}=3119.20$ & \\
\hline $\mathrm{x}_{1}=$ Temperature $\left({ }^{\circ} \mathrm{C}\right)$ & $b_{1}=-0.02$ & 0.642 \\
\hline$x_{2}=$ Time $(\min )$ & $b_{2}=-0.10$ & 0.010 \\
\hline$x_{3}=$ Specific energy $(W-h / g)$ & $b_{3}=24.98$ & 0.022 \\
\hline $\mathrm{x}_{4}=$ Fresh fruit sugar content & $\mathrm{b}_{4}=-39.22$ & 0.018 \\
\hline \multirow{2}{*}{$\begin{array}{l}x_{5}=\text { Initial moisture } \\
\text { content }(\%)\end{array}$} & $b_{5}=-28.23$ & 0.318 \\
\hline & $r^{2}=0.985$ & \\
\hline
\end{tabular}

a Decomposition of the sum or squared errors $\left(\mathrm{SSE}_{\mathrm{Xi}_{\mathrm{i}}}\right)$ indicated the amount $\mathrm{Xi}$ contributes to the prediction of $\mathrm{Y}$.

$\mathrm{SSR}=$ sum or squared regression tion of puff grapes to be estimated at about $70{ }^{\circ} \mathrm{C}$ with a specific energy of $0.880 \mathrm{~W}-\mathrm{h} / \mathrm{g}$. Actual measured process parameters shown in Table 1 were a process temperature of $71^{\circ} \mathrm{C}$ at a specific energy of $0.742 \mathrm{~W}-\mathrm{h} / \mathrm{g}$.

Prediction of FMC of grapes dried by Clary and others (2005) using incremental levels of MW power had $r^{2}=0.875$ compared to $r^{2}=$ 0.942 for prediction of FMC in this study where product temperature was used to control MW power.

\section{Retention of elements and compounds}

On the basis of the element and compound analysis, a concentration effect was observed between the fresh and dry fruit among

Table 4 - Element and compound contents of MW vacuum dried grapes, sun-dried raisins, and fresh grapes

\begin{tabular}{lrrr}
\hline & \multicolumn{3}{c}{ (content per 100 gm) } \\
\cline { 2 - 4 } Compound & $\begin{array}{c}\text { Microwave } \\
\text { vacuuma }\end{array}$ & $\begin{array}{c}\text { Sun-dried } \\
\text { raisins }\end{array}$ & $\begin{array}{c}\text { Fresh } \\
\text { fruit }\end{array}$ \\
\hline Protein (NX6.25)(g) & 3.63 & 3.10 & 1.08 \\
Fat (g) & 0.00 & 0.11 & 0.18 \\
Carbohydrate (g) & 90.99 & 89.02 & 24.91 \\
Calories (4-9-4\#) & 378.00 & 369.00 & 106.00 \\
Vitamin A (I.U.) & 175.00 & $n . d$. & 80.00 \\
Vitamin C (mg) & 12.50 & 8.83 & 0.30 \\
Thiamine (mg) & 0.29 & 0.17 & 0.04 \\
Riboflavin (mg) & 0.31 & 0.15 & 0.06 \\
Niacin (mg) & 1.54 & 2.58 & 0.50 \\
Calcium (mg) & 54.40 & 54.30 & 21.10 \\
Iron (mg) & 1.38 & 3.74 & 1.02 \\
Sodium (mg) & 3.90 & 3.60 & 3.60 \\
Potassium (mg) & 900.00 & 870.00 & 200.00 \\
Crude fiber (g) & 0.79 & 1.18 & 0.38 \\
Moisture (g) & 2.68 & 5.49 & 73.27 \\
Ash (g) & 2.70 & 2.28 & 0.56 \\
Sulfur dioxide (ppm) & 38.00 & 47.00 & 16.00 \\
Dietary fiber (\%) & 3.90 & 6.30 & 1.60 \\
\hline
\end{tabular}

a MW vacuum drying: $106 \mathrm{~min}, 71^{\circ} \mathrm{C}$.

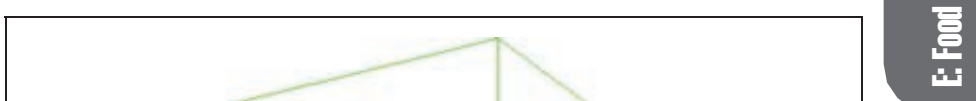

Figure 7-Regression surface plot of the effect of total specific energy and temperature on puffed character of dried grapes 
the elements not suspected to be susceptible to heat (Table 4). Since the element and compound content was based on $100 \mathrm{~g}$ samples, a ratio of the content value in the dried fruit was about 4.5 times greater than in the fresh grapes. For example, potassium content was in fact 4.5 times greater in the dried fruit samples compared to the fresh grapes. Similar ratios were found for carbohydrate, calories, elements including calcium, iron and sodium, and fiber, ash, and sulfur dioxide.

In regard to the effect of heat on heat sensitive nutrients, samples of fresh grapes dried at $71^{\circ} \mathrm{C}$ using MW vacuum dehydration exhibited somewhat better preservation of vitamins compared to sundried grapes (raisins). The most noticeable difference was vitamin A, which was measured at 378 I.U./ 100 g compared to nondetected in raisins made from the same grapes (Table 4). Vitamin A was detected in the fresh fruit at 80 I.U. but not detected in the raisins. This is consistent with the findings of Lin and others (1998). Vitamin C content was also higher in the MW-vacuum-dried samples as was thiamine and riboflavin.

The results of this research were applied to a continuous process MW vacuum dehydration system that operated at a feed rate of $13.6 \mathrm{~kg} / \mathrm{h}$ fresh grapes. FMC was $4.5 \%$ (wb) and specific energy was $0.808 \mathrm{~W}$-h/g fresh grapes.

\section{Conclusions}

The tests described in this article indicated use of temperature 1 measurement to control the MW power application to grapes in the MW vacuum process provided a discrete, real-time control of the process to produce dried grapes with better retention of fresh character, including nutritional composition compared to sun-dried raisins. The MW-vacuum-dried grapes under temperature control improved MW power control and product quality compared to the use of fixed levels and incrementally staged MW power applications. The real-time control modulated MW power based on the actual temperature of the grapes. This reduced temperature overrun and decreased the specific energy required to dry grapes.

\section{Acknowledgments}

The authors acknowledge the support of the Agricultural Research Center, Washington State Univ., California Agricultural Technology Inst., California State Univ., Fresno and Unilever-Best Foods.

\section{References}

AOAC. 1980. Moisture in dried fruits. In: Horowitz W, editor. Official method of analysis of the Association of Official Analytical Chemists, 13th ed. Washington, D.C.: AOAC.

Clary CD, Wang S, Petrucci VE. 2005. Fixed and incremental levels of microwave power application on drying grapes under vacuum. J Food Sci 70:344-9.

Cui ZW, Xu SY, Sun DW. 2004. Microwave vacuum drying kinetics of carrot slices. J Food Sci 65:157-64.

Drouzas AE, Schubert H. 1996. Microwave application in vacuum drying of fruits J Food Eng 28:203-9.

Drouzas AE, Tsami E, Saravacos GD. 1999. Microwave/vacuum drying of model fruit gels. J Food Eng 39:117-22.

FASOnline. 2002. World raisin situation and outlook. Available from: www.fas usda.gov/htp2/circular/2000/00-07/raisin.htm.

Feng H, Tang J. 1998. Microwave finish drying of diced apples in a spouted bed. J Food Sci 63:679-82.

Giri SK, Prasad S. 2007. Drying kinetics and rehydration characteristics of microwave vacuum and convective hot-air dried mushrooms. J Food Eng 78:512-21.

Hu QG, Zhang M, Mujumdar AS, Xiao GN, Sun JC. 2006. Drying of edamames by hot air and vacuum microwave combination. J Food Eng 77:977-82.

Kizlink V. 1990. Principles of food preservation. Amsterdam. The Netherlands: Elsevier Science Publishers.

Lin TM, Durance TD, Scaman CH. 1998. Characterization of vacuum microwave, air and freeze dried carrot slices. Food Res Int 31:111-7.

Lu L, Tang J, Ran X. 1999. Temperature and moisture changes during microwave drying of sliced food. Drying Technol 17:413-32.

McMinn VAM. 2006. Thin-layer modeling of the convective, microwave, microwaveconvective and microwave vacuum drying of lactose powder. J Food Eng 72:113-23. Minitab 14. 2003. Minitab manual v14. State College, Pa.: Minitab.

Mousa N, Farid M. 2002. Microwave vacuum drying of banana slices. Drying Technol 20:2055-66.

Mui WWY, Durance TD, Scaman CH. 2002. Flavor and texture of banana chips dried by combinations of hot air, vacuum, and microwave processing. J Agric Food Chem 50:1883-9.

Petrucci VE, Clary CD, editors. 2002. A treatise on raisin production and processing Clovis, Calif.: Malcolm Media Press.

Ratti C. 2001. Hot air and freeze-drying of high-value foods: a review. J Food Eng 49:311-9.

Schiffmann RF. 1995. Microwave and dielectric drying. In: Handbook of industrial drying, 2nd ed. New York: Marcel Dekker. p 345-71.

Sunjka PS, Rennie TJ, Beaudry C, Raghavan GSV. 2004. Microwave-convective and microwave vacuum drying of cranberries: a comparative studies. Drying Technol 22:1217-31.

Zhang MF, Tang J, Mujumdar AS, Wang S. 2006. Trends in microwave-related drying of fruits and vegetables. Trends Food Sci Technol 17:524-34. 